\title{
Vacuum Ultraviolet Irradiation Treatment for Reducing Gold-Gold Bonding Temperature
}

\author{
Akiko Okada $^{1, * 1}$, Shuichi Shoji ${ }^{1}$, Masatsugu Nimura ${ }^{1, * 1}$, Akitsu Shigetou ${ }^{2}$, \\ Katsuyuki Sakuma ${ }^{3}$ and Jun Mizuno ${ }^{1, * 2}$ \\ ${ }^{1}$ Department of Nanoscience and Nanoengineering, Waseda University, Tokyo 169-8555, Japan \\ ${ }^{2}$ National Institute for Materials Science, Tsukuba 305-0044, Japan \\ ${ }^{3}$ Microelectronics Division, IBM Corporation, NY 12533, USA
}

Low-temperature $\mathrm{Au}-\mathrm{Au}$ bonding was achieved under vacuum ultraviolet irradiation in the presence of oxygen gas $\left(\mathrm{VUV} / \mathrm{O}_{3}\right)$. The $\mathrm{Au}$ surfaces obtained after the $\mathrm{VUV} / \mathrm{O}_{3}$ treatment were analyzed by X-ray photoelectron spectroscopy (XPS) and atomic force microscopy (AFM) measurements. The results indicate that the amount of carbon-based contaminants was dramatically decreased and that there was no serious damage to $\mathrm{Au}$ surfaces caused by the $\mathrm{VUV} / \mathrm{O}_{3}$ treatment. The $\mathrm{Au}-\mathrm{Au}$ bonding temperature was successfully reduced to $150^{\circ} \mathrm{C}$ after the $\mathrm{VUV} /$ $\mathrm{O}_{3}$ treatment. The average shear strength was approximately $56 \mathrm{MPa}$, and cross-sectional scanning electron microscopy (SEM) images of the bonded samples confirmed the absence of voids and cracks. Therefore, VUV $/ \mathrm{O}_{3}$ treatment is highly effective for achieving low-temperature $\mathrm{Au}-\mathrm{Au}$ bonding. [doi:10.2320/matertrans.MF201313]

(Received February 4, 2013; Accepted August 20, 2013; Published October 4, 2013)

Keywords: bonding, gold, flip chip, micro-bump, three-dimensional integration, vacuum ultraviolet

\section{Introduction}

Three-dimensional (3D) chip-stacking technology is an attractive means of reducing interconnect delays in future integrated circuits (ICs) because through-silicon vias (TSVs) and micro-bumps offer shorter wiring distances between the

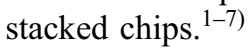

Low-temperature bonding is important for 3D chip stacking in order to avoid various problems arising at high temperatures such as thermal damage to the circuit elements, chip warping and thermal expansion, which may lower the alignment accuracy. Conventionally, proposed low-temperature $\mathrm{Au}-\mathrm{Au}$ bonding techniques have included plasma irradiation $^{8)}$ or ultrasonic bonding. ${ }^{9)}$ However, plasma irradiation cleaning requires high-vacuum conditions (pressure less than $10 \mathrm{~Pa}){ }^{10)}$ which reduces the throughput of the bonding process. On the other hand, it is difficult to bond large chips with many bumps using ultrasonic bonding because the ultrasonic vibration is dispersed on each bump, decreasing the intensity of the vibrations. Furthermore, it is difficult to align chips with a high degree of accuracy because of the ultrasonic vibration.

Vacuum ultraviolet irradiation treatment in the presence of oxygen gas $\left(\mathrm{VUV} / \mathrm{O}_{3}\right)$ can prevent such problems. ${ }^{11)}$ The concept of this treatment is to remove carbon-based organic contaminants with the oxygen radicals excited by VUV, thus causing oxidative degradation and volatilization of the contaminants. This treatment causes no serious damage to the cleaned parts and can be used for wafer-level cleaning. In addition, the treatment system needs only low-vacuum conditions (pressure of $30 \mathrm{kPa}$ ), so the throughput of the bonding process can be higher than that obtained through plasma irradiation cleaning. In this paper, $\mathrm{VUV} / \mathrm{O}_{3}$ treatment was studied as a technique for reducing the $\mathrm{Au}-\mathrm{Au}$ bonding temperature.

\footnotetext{
${ }^{* 1}$ Graduate Student, Waseda University

${ }^{* 2}$ Corresponding author, E-mail: mizuno@waseda.jp
}

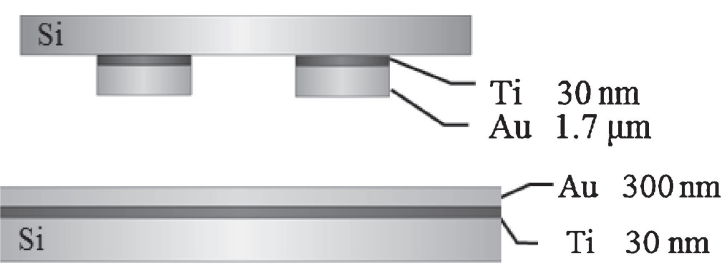

Fig. 1 Schematic illustration of an upper Si chip with Au bumps and a lower Si chip with evaporated Au.

\section{Materials and Procedures}

\subsection{Materials}

Figure 1 shows a cross-sectional schematic illustration of an upper silicon chip with Au bumps and a lower Si substrate with evaporated $\mathrm{Au}$. The diameter, pitch and height of the $\mathrm{Au}$ bumps are 10, 100 and $1.7 \mu \mathrm{m}$, respectively. The bump count on the chip is 900. Furthermore, 30-nm-thick Ti and 300-nmthick Au films were evaporated on the lower silicon substrate.

The process for fabrication of an Au bump is shown schematically in Fig. 2 and proceeds as follows: (a) a seed layer composed of 30-nm-thick Ti and 100-nm-thick Au layers is evaporated on a $\mathrm{Si}$ chip. (b) A photoresist (AZP4620, AZ Electronic Materials Co., Ltd.) is patterned using photolithography. (c) Au is electroplated within the resist pattern. (d) The resist is removed by an organic solvent. (e) The seed layer is removed by performing Ar ion milling.

Figure 3 shows an optical micrograph of a chip with $\mathrm{Au}$ bumps and an SEM image of a single Au bump.

\subsection{Procedures}

\subsection{1 $\mathrm{VUV} / \mathrm{O}_{3}$ surface treatment}

Figure 4 shows a cross-sectional illustration of the $\mathrm{VUV} / \mathrm{O}_{3}$ treatment system (Ushio UER 20-172), which is composed of a lamp house and an irradiation chamber. The UV light has a central wavelength of $172 \mathrm{~nm}$ and a full width at half maximum (FWHM) of $14 \mathrm{~nm}$. Light with a wave- 
(a) EB evaporation of seed layer

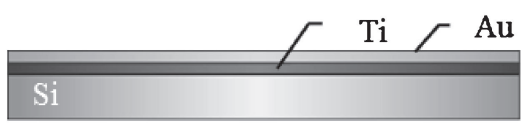

(b) Photolithography

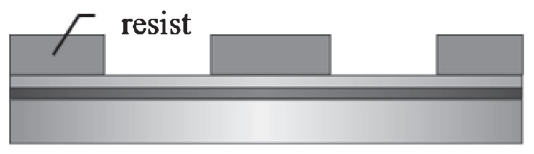

(c) Electroplating

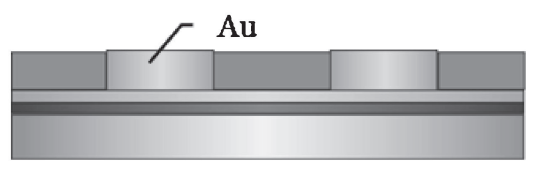

(d) Removal of resist

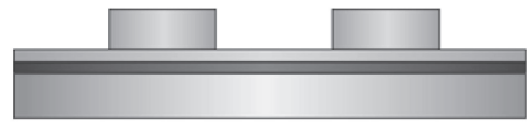

(e) Ar ion milling of seed layer

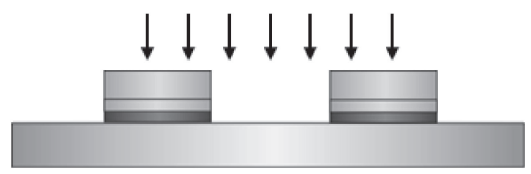

Fig. 2 Schematic diagram of process for fabrication of Au bumps.
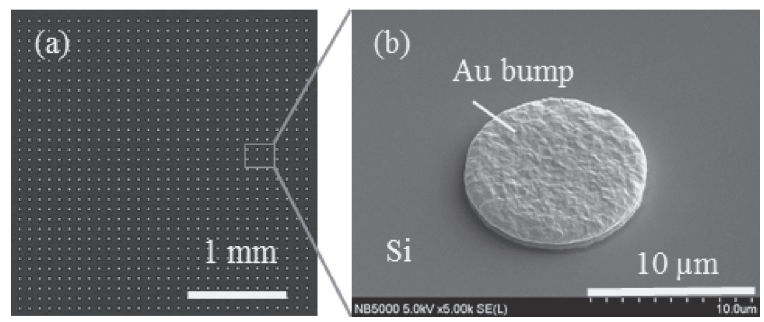

Fig. 3 (a) Optical micrograph of chip with Au bumps and (b) SEM image of a single Au bump.

length shorter than $175 \mathrm{~nm}$ can produce oxygen radicals by directly decomposing oxygen. The UV light, transmitted through the glass window of the lamp house, causes chemical reactions in the irradiation chamber. Oxygen radicals generated by oxygen and ozone cause oxidative degradation that volatilizes the contaminants. Thus, organic contaminants were removed via these reactions. Before flip-chip bonding, both the upper chip and the lower substrate were subjected to $\mathrm{VUV} / \mathrm{O}_{3}$ treatment. The $\mathrm{VUV} / \mathrm{O}_{3}$ treatment conditions are shown in Table 1. The treatment was carried out at room temperature in a chamber with an ozone pressure of $30 \mathrm{kPa}$. The exposure time for each sample was $5 \mathrm{~min}$.

\subsubsection{Bonding process}

The $\mathrm{Au}-\mathrm{Au}$ bonding was carried out both with and without $\mathrm{VUV} / \mathrm{O}_{3}$ treatment such that the effect of the $\mathrm{VUV} / \mathrm{O}_{3}$ treatment could be evaluated. After both an upper chip and

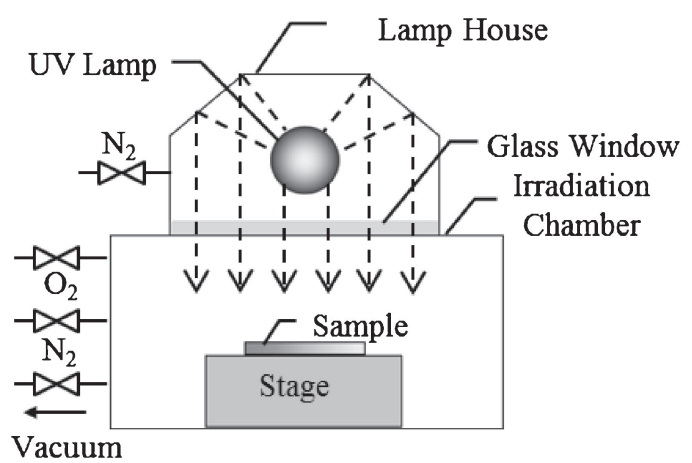

Fig. 4 Cross-sectional illustration of $\mathrm{VUV} / \mathrm{O}_{3}$ treatment system.

Table $1 \mathrm{VUV} / \mathrm{O}_{3}$ treatment conditions.

\begin{tabular}{ll}
\hline Lamp power $P / \mathrm{W}$ & 20 \\
$\mathrm{UV}$ wavelength $\lambda / \mathrm{nm}$ & 172 \\
Light intensity $E / \mathrm{mW} \cdot \mathrm{cm}^{-2}$ & 10 \\
Exposure time $t / \mathrm{min}$ & 5 \\
Temperature $T /{ }^{\circ} \mathrm{C}$ & 24 \\
Chamber pressure under oxygen gas $p / \mathrm{Pa}$ & $3.0 \times 10^{4}$ \\
\hline
\end{tabular}

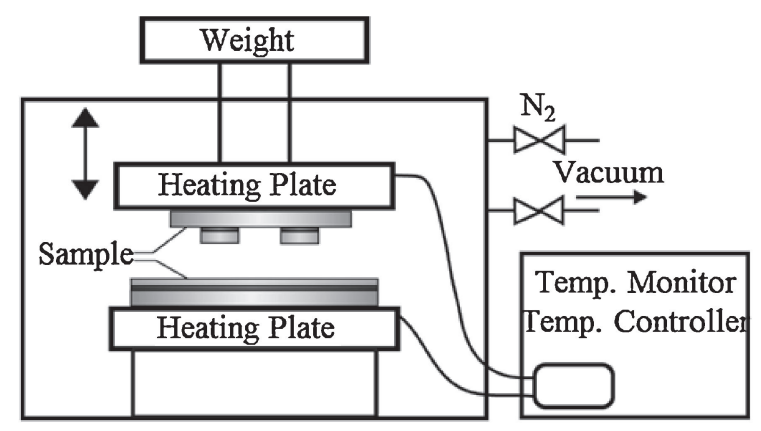

Fig. 5 Cross-sectional illustration of bonding equipment.

Table 2 Bonding conditions.

\begin{tabular}{ll}
\hline Temperature $T /{ }^{\circ} \mathrm{C}$ & 150 \\
Bonding pressure $P / \mathrm{MPa}$ & 262 \\
Bonding time $t / \mathrm{min}$ & 10,20 \\
Chamber pressure $P_{\mathrm{c}} / \mathrm{Pa}$ & $<100$ \\
\hline
\end{tabular}

a lower chip were subjected to the $\mathrm{VUV} / \mathrm{O}_{3}$ treatment, the chip with $\mathrm{Au}$ bumps was bonded to the evaporated-Au chip surface as soon as possible to prevent adhesion of contaminants from the ambient air after the $\mathrm{VUV} / \mathrm{O}_{3}$ treatment. Figure 5 shows a cross-sectional illustration of the bonding equipment. First, the processing chamber was evacuated to a pressure of less than $100 \mathrm{~Pa}$. Then, the bonding pressure and temperature were applied. Both the upper chip and the lower chip were heated by carefully controlled electric heaters above and below the chips. The bonding conditions are shown in Table 2. The bonding temperature was $150^{\circ} \mathrm{C}$, and the bonding times, which are the times for which the samples were kept at the bonding temperature, were 10 and $20 \mathrm{~min}$. The bonding pressure was $262 \mathrm{MPa}$. 

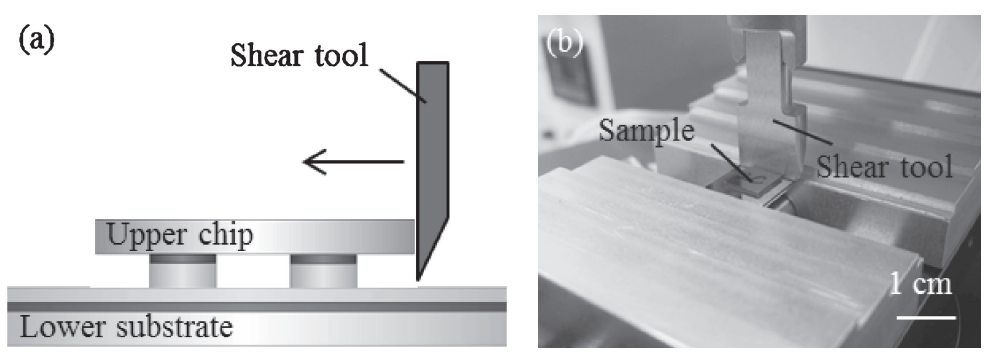

Fig. 6 (a) Cross-sectional illustration and (b) photograph of the die shear test setup.

(a)

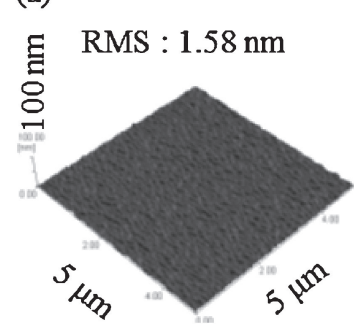

(b)

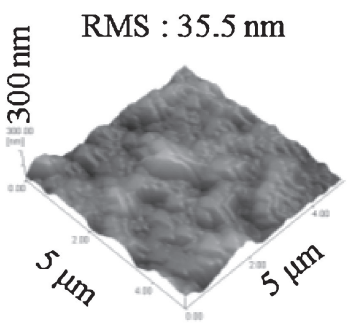

Fig. 7 AFM image of untreated (a) evaporated-Au chip surface and (b) Au bump surface.

\subsubsection{Characterization}

Atomic force microscopy (AFM) measurements (using a SHIMADZU SPM-9600) were performed to examine the surface roughness and morphology of the $\mathrm{Au}$ bumps and the evaporated-Au chip surface before and after $\mathrm{VUV} / \mathrm{O}_{3}$ treatment.

X-ray photoelectron spectroscopy (XPS) was used to investigate the composition of the $\mathrm{Au}$ surfaces before and after VUV $/ \mathrm{O}_{3}$ treatment. XPS measurements (using a Japan Electron Optics Laboratory JPS-9010TR) were performed using $\mathrm{Mg} \mathrm{K} \alpha(1253.6 \mathrm{eV})$ radiation at $100 \mathrm{~W}(10 \mathrm{kV}$, $10 \mathrm{~mA})$.

After the bonding, the shear strengths of the samples, bonded both with and without $\mathrm{VUV} / \mathrm{O}_{3}$ treatment, were measured by performing shear strength tests (using a Dage Japan Dage-4000). Figure 6 shows a cross-sectional illustration and a photograph of the die shear test setup. The bonded sample was horizontally strained by the shear tool, and the stress at rupture was measured. The shear tool speed in the die shear test was $50 \mu \mathrm{m} / \mathrm{s}$.

\section{Results and Discussion}

\subsection{Surface analysis}

Figures 7 and 8 show AFM images of the evaporated-Au chip surface and an Au bump surface, respectively, before and after $\mathrm{VUV} / \mathrm{O}_{3}$ treatment. The AFM-scanned area was $5 \times 5 \mu \mathrm{m}$. The root mean square (RMS) surface roughness of the untreated evaporated-Au chip surface and an untreated Au bump were 1.58 and $35.5 \mathrm{~nm}$, respectively. The RMS surface roughness of the $\mathrm{VUV} / \mathrm{O}_{3}$-treated evaporated-Au chip surface and a VUV/O $/ \mathrm{O}_{3}$-treated $\mathrm{Au}$ bump were 2.07 and $36.3 \mathrm{~nm}$, respectively. The differences between the surface roughness values before and after $\mathrm{VUV} / \mathrm{O}_{3}$ treatment were minimal. (a)

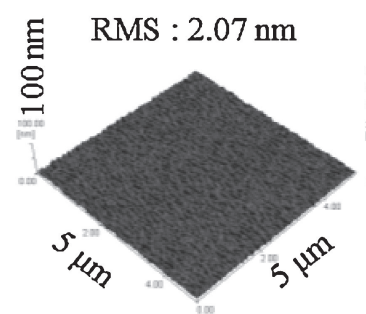

(b)

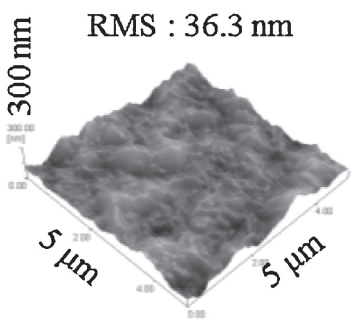

Fig. 8 AFM image of VUV/O $/ \mathrm{O}_{3}$-treated (a) evaporated-Au chip surface and (b) an Au bump surface.
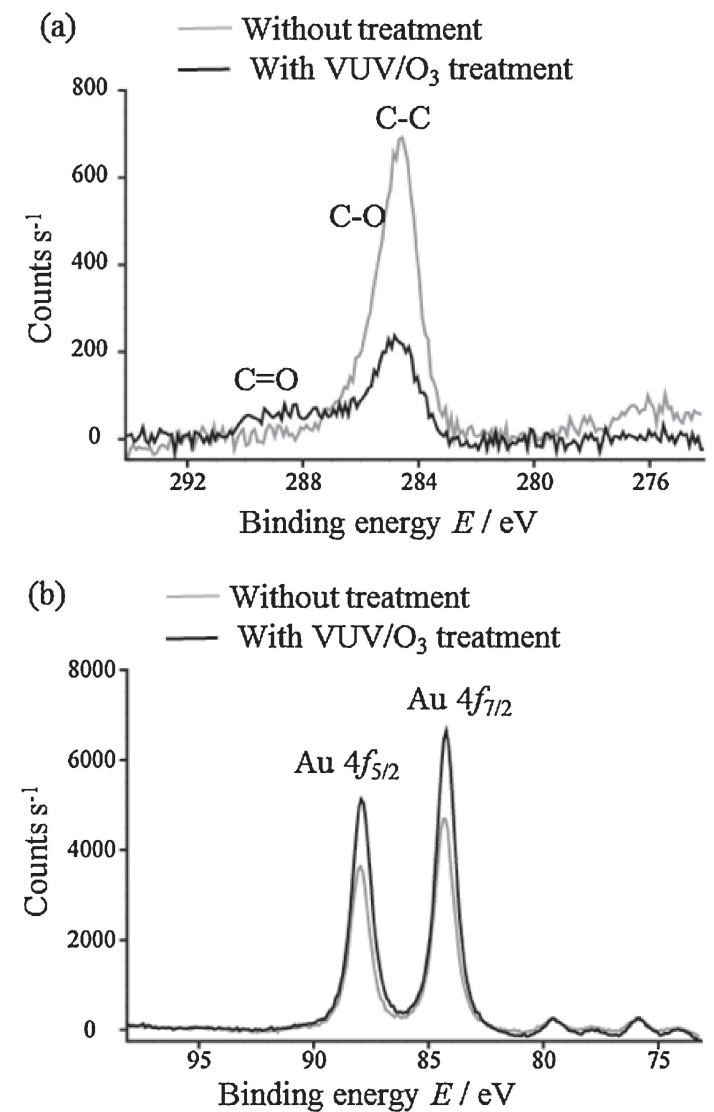

Fig. 9 Narrow-scan (a) C 1s and (b) Au 4f XPS spectra for the evaporated$\mathrm{Au}$ chip surface before and after $\mathrm{VUV} / \mathrm{O}_{3}$ treatment.

Figures 9 and 10 show narrow-scan $\mathrm{C} \mathrm{1s}$ and $\mathrm{Au} 4 \mathrm{f}$ XPS spectra before and after $\mathrm{VUV} / \mathrm{O}_{3}$ treatment of the evaporated-Au chip surface and an $\mathrm{Au}$ bump surface, respectively. In Figs. 9(a) and 10(a), there is a large peak 

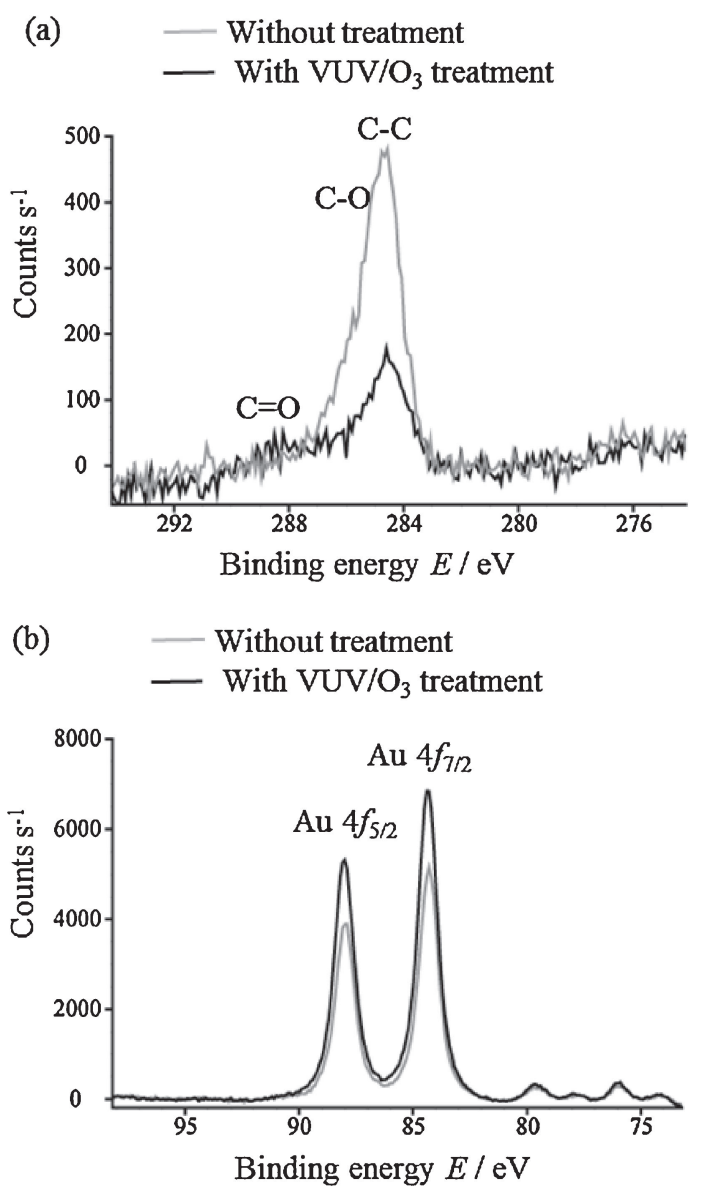

Fig. 10 Narrow-scan (a) C 1s and (b) Au 4f XPS spectra for the Au bump surface before and after $\mathrm{VUV} / \mathrm{O}_{3}$ treatment.

attributable to $\mathrm{C}-\mathrm{C}$ bonds at $284.6 \mathrm{eV}$ and relatively small peaks attributable to $\mathrm{C}-\mathrm{O}$ bonds at $286.5 \mathrm{eV}$ and $\mathrm{O}-\mathrm{C}=\mathrm{O}$ bonds at $288.7 \mathrm{eV}$. After $\mathrm{VUV} / \mathrm{O}_{3}$ treatment, the $\mathrm{C}-\mathrm{C}$ and $\mathrm{C}-\mathrm{O}$ bond peak strengths dramatically decreased, which shows that organic contaminants on the evaporated-Au chip surface and on the Au bump surface were removed by the $\mathrm{VUV} / \mathrm{O}_{3}$ treatment. The reason that permits removal of organic contaminants by the treatment is considered to be the following. The bond energies of $\mathrm{C}-\mathrm{C}$ bonds and $\mathrm{C}-\mathrm{O}$ bonds are 348 and $358 \mathrm{~kJ} / \mathrm{mol}$, respectively. Therefore, the $172 \mathrm{~nm}$ VUV light, whose photon energy is $697.5 \mathrm{~kJ} / \mathrm{mol}$, has sufficient energy to rupture the chemical bonds of molecules, thereby forming organic contaminants. Thus, organic contaminants were split into smaller components by the VUV light. After this photodissociation reaction, oxygen radicals, which were also produced by photodissociation of oxygen and ozone molecules, reacted with those organic components and formed water and carbon oxides. These compounds were volatilized and eventually removed at the surface. Figures 9(b) and 10(b) show two distinct peaks corresponding to $\mathrm{Au} 4 \mathrm{f}_{7 / 2}$ at $84.0 \mathrm{eV}$ and $\mathrm{Au} 4 \mathrm{f}_{5 / 2}$ at $87.9 \mathrm{eV}$. The peak intensity in the $\mathrm{Au} 4 \mathrm{f}$ spectra increased after the $\mathrm{VUV} / \mathrm{O}_{3}$ treatment, which means that the purity of the $\mathrm{Au}$ on the surfaces increased because organic contaminants were removed. As shown in Tables 3 and 4, the carbon concentration decreased by almost $30 \%$ and the $\mathrm{Au}$ concentration increased by almost $23 \%$ after the $\mathrm{VUV} / \mathrm{O}_{3}$ treatment.
Table 3 Surface elemental compositions of evaporated-Au chip surface determined by XPS analysis.

\begin{tabular}{lccc}
\hline \multirow{2}{*}{ Surface treatment } & \multicolumn{3}{c}{ Atomic concentration \% } \\
\cline { 2 - 4 } & $\mathrm{C}$ & $\mathrm{O}$ & $\mathrm{Au}$ \\
\hline No treatment & 51.6 & 8.5 & 39.9 \\
VUV $/ \mathrm{O}_{3}$ treatment & 18.0 & 17.6 & 64.4 \\
\hline
\end{tabular}

Table 4 Surface elemental compositions of Au bump surface determined by XPS analysis.

\begin{tabular}{lccc}
\hline \multirow{2}{*}{ Surface treatment } & \multicolumn{3}{c}{ Atomic concentration \% } \\
\cline { 2 - 4 } & $\mathrm{C}$ & $\mathrm{O}$ & $\mathrm{Au}$ \\
\hline No treatment & 44.0 & 9.0 & 47.1 \\
$\mathrm{VUV} / \mathrm{O}_{3}$ treatment & 18.1 & 12.3 & 70.0 \\
\hline
\end{tabular}

Table 5 Shear strengths of samples bonded with and without VUV/O 3 treatment.

\begin{tabular}{lcc}
\hline Surface treatment & $\begin{array}{c}\text { Bonding time } \\
t / \text { min }\end{array}$ & $\begin{array}{c}\text { Shear strength } \\
P / \mathrm{MPa}\end{array}$ \\
\hline \multirow{2}{*}{ No treatment } & 10 & - \\
\hline $\mathrm{VUV} / \mathrm{O}_{3}$ treatment & 20 & - \\
\hline
\end{tabular}

\subsection{Shear strength testing}

The shear strengths per unit area of the samples bonded with and without VUV $/ \mathrm{O}_{3}$ treatment are shown in Table 5. The Au bumps were bonded to the evaporated-Au chip surface at $150^{\circ} \mathrm{C}$ after the $\mathrm{VUV} / \mathrm{O}_{3}$ treatment. The upper chips were easily broken away from the lower substrates using tweezers when no $\mathrm{VUV} / \mathrm{O}_{3}$ treatment was performed. This is because organic contaminants remained at the interface during the application of bonding pressure, and prevented $\mathrm{Au}$ atoms from diffusing through the contaminant layer to the other side when no treatment was performed. In contrast, the Au bump surface got closer to the evaporated$\mathrm{Au}$ chip surface during the bonding process due to the removal of carbon-based contaminants by the $\mathrm{VUV} / \mathrm{O}_{3}$ treatment. The treatment promoted interface diffusion, thus forming stronger metallurgical bonds between the surfaces over a wider bonding area.

Figures 11 and 12 show cross-sectional SEM images of the samples bonded for 10 and $20 \mathrm{~min}$, respectively, after VUV/ $\mathrm{O}_{3}$ treatments. As shown in the figures, nanometer-sized voids are present at the $\mathrm{Au}-\mathrm{Au}$ bonding interface. However, there are no obvious voids in a large section of the bonding area. This is because the RMS surface roughness of the Au bump is about $36 \mathrm{~nm}$, which is more than ten times larger than that of the Au thin film. Therefore, the surface asperities of the Au bumps could not deform completely. Furthermore, there were no specific differences between the shear strengths and the bonding interfaces of the samples bonded for 10 and $20 \mathrm{~min}$. These results demonstrate that sufficient interfacial diffusion was promoted within $10 \mathrm{~min}$. 


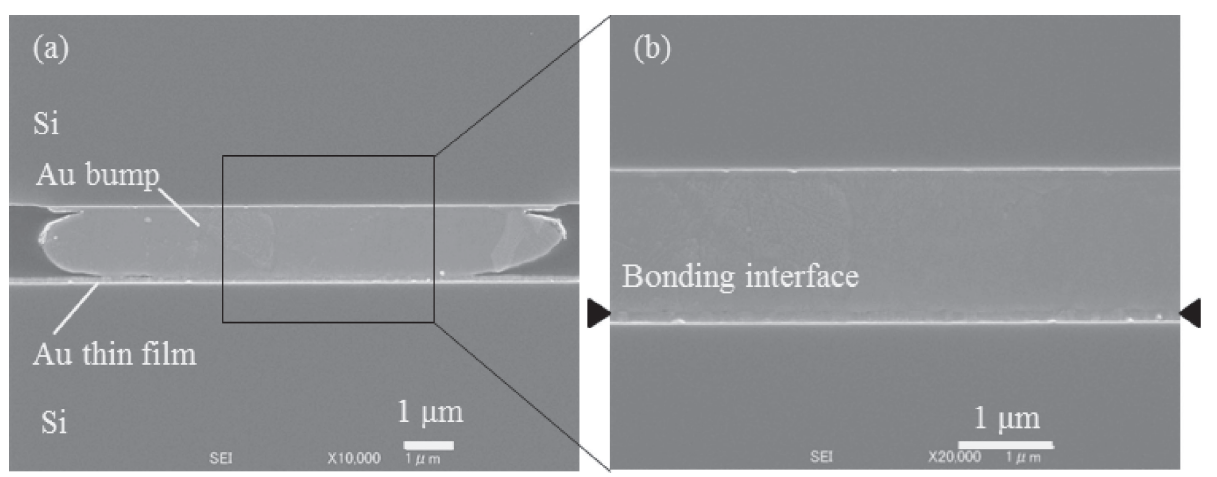

Fig. 11 Cross-sectional SEM images of (a) a sample bonded for $10 \mathrm{~min}$ and (b) the bonding interface of the sample.

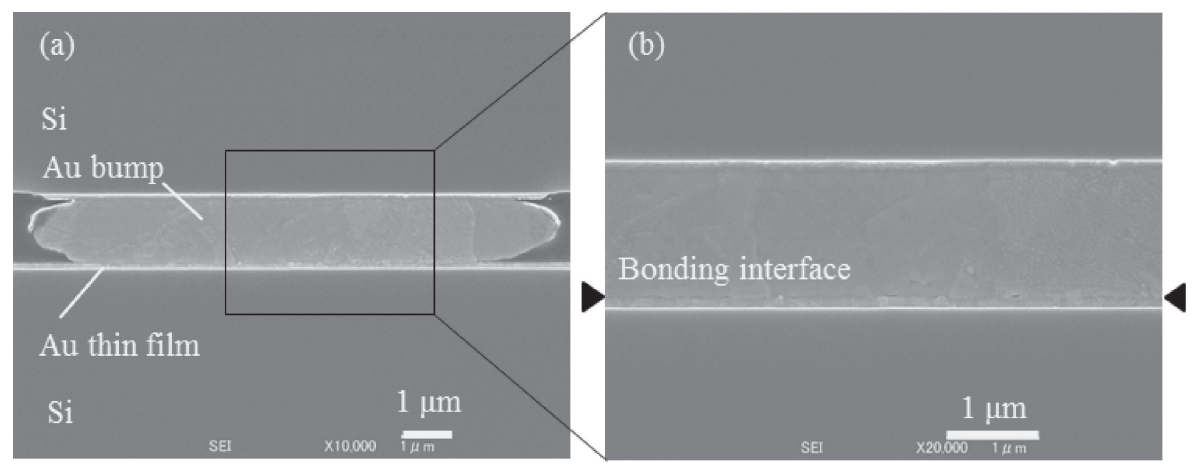

Fig. 12 Cross-sectional SEM images of (a) a sample bonded for $20 \mathrm{~min}$ and (b) the bonding interface of the sample.

\section{Conclusion}

In this study, $\mathrm{Au}-\mathrm{Au}$ bonding was achieved at $150^{\circ} \mathrm{C}$ by performing $\mathrm{VUV} / \mathrm{O}_{3}$ treatments. XPS and AFM results showed that the amounts of carbon-based organic contaminants were significantly decreased by the $\mathrm{VUV} / \mathrm{O}_{3}$ treatment without any damage to the $\mathrm{Au}$ surfaces. Furthermore, the SEM observation showed no obvious voids at the bonding interface. These results indicate that interface diffusion was promoted by the removal of organic contaminants during the $\mathrm{VUV} / \mathrm{O}_{3}$ treatment, which led to the formation of strong metallurgical bonds at the bonding interface. Therefore, $\mathrm{VUV} / \mathrm{O}_{3}$ treatment is highly effective for reducing the $\mathrm{Au}-$ $\mathrm{Au}$ bonding temperature.

\section{Acknowledgments}

This work is partly supported by Japan Ministry of Education, Culture, Sports, Science and Technology (MEXT) Grant-in-Aid for Scientific Basic Research (S) No. 23226010 and Specially Promoted Research "Establishment of Electrochemical Device Engineering". The authors would also like to acknowledge support and encouragement for members of the Nano Technology Research center.

\section{REFERENCES}

1) K. Sakuma, N. Nagai, M. Saito, J. Mizuno and S. Shoji: IEEJ Trans. Electr. Electron. Eng. 4 (2009) 339-344.

2) M. Koyanagi, H. Kurino, K. W. Lee, K. Sakuma, N. Miyakawa and H. Itani: IEEE Micro 18 (1998) 17-22.

3) R. R. Tummala: IEEE Trans. Adv. Packag. 27 (2004) 241-249.

4) K. Sakuma, P. S. Andry, C. K. Tsang, S. L. Wright, B. Dang, C. S. Patel, B. C. Webb, J. Maria, E. J. Sprogis, S. K. Kang, R. J. Polastre, R. R. Horton and J. U. Knickerbocker: IBM J. Res. Dev. 52 (2008) 611-622.

5) G. H. Loh, Y. Xie and B. Black: IEEE Micro 27 (2007) 31-48.

6) J. U. Knickerbocker, P. S. Andry, B. Dang, R. R. Horton, C. S. Patel, R. J. Polastre, K. Sakuma, E. S. Sprogis, C. K. Tsang, B. C. Webb and S. L. Wright: Proc. 58th Electronic Components and Technology Conf., (Lake Buena Vista, Florida, 2008) pp. 538-543.

7) S. J. Koester, A. M. Young, R. R. Yu, S. Purushothaman, K. N. Chen, D. C. La Tulipe, Jr., N. Rana, L. Shi, M. R. Wordeman and E. J. Sprogis: IBM J. Res. Dev. 52 (2008) 583-597.

8) E. Higurashi, D. Chino, T. Suga and R. Sawada: IEEE J. Sel. Top. Quantum Electron. 15 (2009) 1500-1505.

9) S. Tukiyama, T. Sugimoto and Y. Ohno: Proc. 7th IEEE Electronics Packaging Technology Conf., (Singapore, 2005) pp. 792-796.

10) Y. H. Wang and T. Suga: Proc. 58th Electronic Components and Technology Conf., (Lake Buena Vista, Florida, 2008) pp. 944-949.

11) N. Unami, K. Sakuma, J. Mizuno and S. Shoji: Jpn. J. Appl. Phys. 49 (2010) 06GN12. 